\title{
Ecological Construction Mode of Soil and Water Conservation in the Three Gorges Reservoir Area
}

\author{
$\mathrm{Xi} \mathrm{He}{ }^{1^{*}}$ \\ ${ }^{1}$ School of Architecture and Urban Planning, Chongqing University. No.174, Shapingba, Chongqing, 400044, China
}

\begin{abstract}
The Three Gorges Reservoir Area is an important ecological barrier and an important area of water conservation in China. Due to natural and man-made factors, the regional urbanization process is accompanied by soil erosion. In recent years, by actively implementing measures such as tree planting and afforestation, water and soil conservation projects, the forest coverage rate in the Chongqing Three Gorges Reservoir area has increased significantly, and soil erosion has been initially controlled. But the task of environmental protection in the Three Gorges Reservoir area is still arduous. This research analyzed the causes of soil erosion caused by the urban process, by collected and combed the data of soil erosion in the Three Gorges Reservoir area of Chongqing over the years. The causes of soil erosion in the Three Gorges Reservoir area caused by the urbanization process were deeply analyzed, we proposed to improve legislation and supervision; strengthen publicity and education of soil and water conservation; adopt new technology and technology and other governance countermeasures. The Three Gorges Reservoir is an important ecological barrier in the upper reaches of the Yangtze River. The control of soil erosion in the area has important ecological and social benefits for protecting the ecological environment of the Yangtze River Basin in China.
\end{abstract}

\section{Status of Soil and Water Conservation in the Three Gorges Reservoir Area}

The Three Gorges Reservoir area is located in the slope area of the second step of Chinese three major geomorphic steps, which is an important ecological barrier in the upper reaches of the Yangtze River, also as one of the centre of heavy rains in China. In the reservoir area, there are overlapping mountains, steep terrain, deep valleys, rapid water, and strong external dynamic erosion. The mountains are fragmented, ravines are vertical and horizontal, and the ecological environment is fragile. There are potential conditions for water and soil erosion; weak rock formations that were easily weathered when widely exposed, which provided a rich source of material for water and soil erosion, due to the rapid population growth and the neglect of water and soil conservation in some development and construction projects, which has brought great harm to agricultural production and people's lives [1]. According to the 2019 Chongqing Municipal Soil and Water Conservation Bulletin, at the end of 2019, the total area of soil erosion in the city was 25,400 square kilometres(Table 1), accounting for $30.89 \%$ of the total land area. The main area was water erosion, of which the mildly eroded area accounted for $75.15 \%$ of the soil erosion area. The moderately eroded area accounted for $14.42 \%$ of the total, the strongly eroded area accounted for $8.17 \%$ of the total, the extremely strongly eroded area accounted for $2.01 \%$ of the total, and the severely eroded area accounted for $0.25 \%$ of the total [2].

Table 1. Soil Erosion Area of Different Land Types in the Three Gorges Reservoir Area in 2019.

\begin{tabular}{|c|c|}
\hline Land type & $\begin{array}{c}\text { Soil erosion area } \\
\text { (square kilometres) }\end{array}$ \\
\hline Woodland & 16214.29 \\
\hline Arable land & 7670.10 \\
\hline $\begin{array}{c}\text { Construction } \\
\text { land }\end{array}$ & 589.91 \\
\hline Garden & 568.01 \\
\hline $\begin{array}{c}\text { Grassland } \\
\text { Land for } \\
\text { transportation }\end{array}$ & 360.79 \\
\hline Other land & 36.38 \\
\hline Total & 5.09 \\
\hline
\end{tabular}

Now, the Chinese government is paying more and more attention to ecological and environmental protection. The Three Gorges Reservoir area is an important ecological barrier in China. In recent years, by actively implementing measures such as tree planting and afforestation and water and soil conservation projects, the forest coverage rate in the Three Gorges

\footnotetext{
* Corresponding author: 229647244@qq.com
} 
Reservoir area of Chongqing has increased to $50.2 \%$, the soil water retention capacity has increased by $63 \%$, the annual reduction of soil erosion is about 150 million tons, and soil erosion has been initially controlled. Although good results have been achieved, the task of environmental protection in the Three Gorges Reservoir area is still arduous. This research analyzed the causes of soil erosion caused by the urban process, by collected and combed the data of soil erosion in the Three Gorges Reservoir area of Chongqing over the years. Then Proposed targeted suggestions based on in-depth analysis of the problem.

\section{Causes of Urban Soil Erosion in the Three Gorges Reservoir Area}

Compared with natural factors and human factors, human factors played a leading role in the causes of soil erosion in the urban development and construction of the Three Gorges Reservoir area. The special topography, soil and rainfall conditions of the reservoir area are the natural conditions for soil erosion in the reservoir area, and the unreasonable human development in the process of urbanization has caused or aggravated the soil erosion in this area.

\subsection{Awareness of soil and water conservation needs to be further improved}

Some small construction projects may not have prepared soil and water conservation plans. In addition, in the compilation of urban soil and water conservation plans, there were a widespread phenomenon that emphasis was placed on soil and water conservation, and soil erosion control measures were relatively comprehensive, but water conservation measures was not enough attention. Soil conservation measures include covering, enclosure, and topsoil stripping to prepare trees and grasses. Water conservation mainly uses permeable bricks to increase rainwater infiltration, and tree and grass planting to increase greening rate. The above-mentioned water conservation measures were theoretically effective. However, due to the concentration of precipitation in the Three Gorges Reservoir area and the frequent occurrence of heavy rains, it is not very practical in practical applications. Effective water conservation effects are not achieved, resulting in the loss of a large amount of rainwater resources in the city and cannot effectively prevent the city Floods. For example, artificial landscapes such as rockery are often arranged in some newly-built residential communities. If all the green areas in the community are recessed by $5-10 \mathrm{~cm}$, it does not meet people's aesthetic standards. Even if the turf is designed as a recessed land, it cannot adapt to long-term rain soaking. Therefore, even if many real estate development projects have a recessed green space design in the plan, the construction process of the project cannot be completed according to the plan. The permeable bricks used in urban hardened ground have a certain infiltration effect on light rain and moderate rain. If it is a short-duration rainstorm, the permeable bricks will not seep at all. In addition, affected by human activities, the permeable gap of the permeable brick increases with time. There will be clogging, and the water permeability will gradually weaken, the calculation formula of soil runoff modulus is as follows.

$$
\Delta h=\frac{0.001 M}{\gamma \cdot(1-k)}
$$

In the formula, $\Delta h$ is the thickness of soil erosion $(\mathrm{mm}) ; M$ is the amount of soil loss per unit area $\left(\mathrm{t} / \mathrm{km}^{2}\right)$; $\gamma$ is soil bulk density $\left(\mathrm{g} / \mathrm{cm}^{3}\right)$, based on the average value of each demonstration area during the monitoring year; $k$ is the bare rock rate of the sample plot.

$$
\begin{aligned}
\overline{M_{s}} & =\sum M_{s i} f_{i}=\sum \frac{M_{s i} A_{i}}{A} \\
f_{i} & =\frac{A_{i}}{A}
\end{aligned}
$$

In the formula, $\overline{M s}$ is the soil erosion modulus in the area; $M_{\mathrm{si}}$ is the soil erosion intensity at all levels in the area; $f_{\mathrm{i}}$ is the soil erosion intensity at all levels in the area. The ratio of degree area; $A_{\mathrm{i}}$ is the area of erosion degree at all levels; $A$ is the total area of the area.

\subsection{Incomplete construction planning}

In some urban planning infrastructure construction, water and soil conservation measures were not taken into consideration at the initial stage. Urban infrastructure construction has undergone extensive excavation and filling, which has changed the original topography and landforms, directly occupying and destroying surface vegetation, which caused the land to lose the natural barrier of vegetation. Protection, resulting in exposed surface, damage to the surface soil structure, and reduced soil corrosion resistance; massive mining of rocks, destroying the mountain and surface vegetation, excavating the toe of the slope, cutting the side slope, causing mountain imbalance, plus a large amount of solid waste accumulation on the slope, Increasing the load, leading to continuous occurrence of landslides, lack of blocking measures, under the erosion of rainfall, a large amount of sediment was taken away by rainwater runoff, and accelerated the development of soil erosion.

\subsection{Irregular construction}

The topsoil, sand and gravel and other wastes generated by the basic treatment works of the construction project sometimes were randomly piled up nearby without tamping, and without any protective measures, so that the land is in a loose state, and it is easy to form trenches on the slope surface after encountering water. Corrosion and gully corrosion that affects the mesa, etc. Construction spoil and domestic garbage are dumped into rivers and ditches at will, and sediment is transported downstream or silt up by the action of water flow. In addition, the development and construction generally occupy a large area and the surface area of the 
damaged land. After the project breaks ground, it is excavated at will without protection, forming a large area of bare land and broken ground.

\section{Harm of urban soil erosion}

\subsection{Deterioration of the urban environment}

Large-scale urban development and construction have destroyed a large area of landforms and vegetation, and the surface area of exposed topsoil and hardened ground has increased significantly, which destroyed the original ecosystem [3]. When there is a heavy rain during the flood season, the bare soil and various surface deposits will flow down along with the runoff, causing turbid water to flow across and sludge everywhere.

\subsection{Affect the investment environment}

Clean and tidy is an important symbol of city taste. Unreasonable urban development and construction which have fragmented the surface and caused serious soil erosion. The city appearances dirty, chaotic, and poor, which damages the image of the city and affects the enthusiasm for foreign investment.

\subsection{Endanger the safety of urban flood control}

If a large amount of sediment flows down to nearby rivers and urban sewers, which would causing the river bed to rise and the sewers to block up, greatly reducing the city's flood control standards and causing frequent floods. For example, after the heavy rain in Wulong, Chongqing on June 2, 2016, the entire county was flooded to varying degrees. After the flood receded, a thick layer of silt was left on the streets.

\subsection{Affect the water source}

The Three Gorges reservoir area is an important water conservation area in China. Many development and construction projects are within the scope of urban water source protection areas. If there is a lack of corresponding soil and water conservation measures, a large amount of eroded sediment would enter the water source, which threatening the safety of the water source area, and may cause the water pollution in the Three Gorges Reservoir.

\section{Prevention countermeasures}

Soil erosion in urban development and construction not only affects the urban environment, lowers urban flood control standards, pollutes water sources, and affects the sustainable development of the city, but also causes great harm to the industrial and agricultural production and construction downstream of the city. It is necessary to strengthen governance. Prevent soil erosion in urban development and construction.

\subsection{Strengthen publicity}

In the past, the focus of soil and water conservation was in rural areas, and urban development and construction of soil and water conservation work was always been a weak link. Now we should take into account the phenomena of soil erosion hazards caused by disorderly development and construction, and make full use of various propaganda tools such as radio, television, newspapers, new media, and holding special lectures on soil and water conservation to promote the "Law of Water and Soil Conservation" to the whole society, especially leaders at all levels. And relevant laws and regulations, publicize the importance of urban soil and water conservation, enhance the awareness of water and soil conservation and legal concepts of the whole people, which could raise people's awareness of the urgency of urban soil erosion prevention and control, and increase the sense of responsibility for development and construction according to the law.

\subsection{Strict law enforcement}

According to the existing water and soil conservation laws and regulations, and combine to the specific local conditions, the corresponding regulations or normative documents should be issued. The entire process from project initiation, water conservation plan approval, construction, and acceptance, to putting into use should have supporting regulations. Restrictions to ensure the implementation of the right to supervise, approve and charge fees for soil and water conservation. Urban soil and water conservation laws and regulations should focus on implementing the government's responsibilities for soil and water conservation goals in each functional area of the city, establish a relevant planned soil and water conservation coordination mechanism, clarify key prevention areas and governance areas based on the characteristics of the city, and implement the most stringent production and construction project soil and water conservation management system. Strengthen the management of urban rain and flood and earth and stone, speed up soil erosion control and ecological restoration, implement soil and water conservation monitoring, publicity, and bulletin systems, establish a social supervision mechanism, clarify legal responsibilities, and increase penalties [4]. In addition, it is necessary to establish law enforcement supervision agencies, train law enforcement personnel, improve the quality of law enforcement teams, and strengthen the investigation and handling of major and important cases. Only in this way which could prevent and control of newly added soil erosion in urban development and construction, brought into the track of the legal system to achieve results. For example, Shenzhen has formulated operable local laws, regulations and plans, strengthened the prevention and supervision of soil and water conservation, and issued timely rectification notices in response to the hidden dangers of soil erosion during the construction of various development and construction projects; Shenzhen has also gradually issued rectification notices. The city has created an innovative technology system for urban soil 
and water conservation, such as large-scale development of soil erosion control in flat soil areas, comprehensive improvement of water and soil conservation of bare mountain gaps, comprehensive management of water and soil conservation in drinking water source reservoirs, and strengthening of supervision and management of soil and water conservation in development and construction projects. Constructing a demonstration park for urban soil and water conservation science and technology [5].

\subsection{Make scientific plans}

According to the plan, carry out the investigation of soil erosion in the region gradually, and prepare the urban soil and water conservation plan based on the urban master plan and investigation results, so that soil and water conservation could penetrate into the development and construction, which achieve the simultaneous and coordinated development of urban development and construction, could implement soil and water conservation. The "three simultaneous" system of measures and the main project of the project fundamentally solves the problem between urban development and soil and water conservation.

The urban soil erosion prevention and control work has a large and extensive scope, and it is easier to form an extensive situation. It is necessary to start with planning, construction, management, and monitoring, promote the application of high-tech science and technology, and continuously increase the scientific and technological content in urban soil erosion prevention and control work. For example, Xi'an has adopted new materials and technologies in urban construction to increase rainwater infiltration and reduce surface runoff.

\section{Conclusion}

The Three Gorges Reservoir area is an important ecological barrier and water conservation area in China. However, due to natural and human factors, the process of urbanization in this area was accompanied by soil erosion. In the context of global urbanization, from a long-term and overall perspective, the goals of urban construction soil and water conservation were the same. They are necessary measures for people to adapt to nature, transform nature, and better serve human society. From the perspective of short-term benefits, urban construction, especially real estate development, and other industries' interest-driven industries and the immeasurable nature of the ecological benefits of soil and water conservation have caused urban soil and water conservation to be neglected. However, as the whole society recognizes, the importance of the ecological environment, people's awareness of the importance of soil and water conservation has increased. This research analyzed the causes of soil erosion caused by the urban process, by collected and combed the data of soil erosion in the Three Gorges Reservoir area of Chongqing over the years. The causes of soil erosion in the Three Gorges Reservoir area caused by the urbanization process were deeply analyzed, then proposed that the control of soil erosion in the Three Gorges Reservoir area is a systematic project. On the one hand, it is necessary to improve relevant laws and regulations on soil and water conservation, strengthen law enforcement and supervision, which could avoid soil erosion caused by human factors; on the other hand, it is necessary to strengthen publicity and education to improve the people's soil and water conservation; in addition, we must make full use of modern technology in the control of soil erosion, which to achieve a multiplier effect with half the effort.The process of urbanization in the Three Gorges Reservoir area must be adapted to local conditions and rationally planned, which could put the city construction on the track of a healthy and virtuous circle.

\section{References}

1. Z.H. Du. Soil and Water Conservation and Ecological Environment in the Three Gorges Reservoir Area. China SWC, 5(1999)

2. Water and Soil Conservation Bulletin of Chongqing. (2019)

3. Z.Q. Bai. Practice and Thinking of Urban Construction and Soil and Water Conservation Ecological Environment Construction. Gansu Agri. 19(2016)

4. X.J. Zhou, Y.J. Zhou, S.Y. Chen. Research on the Causes and Prevention Measures of Urban Soil Erosion. Anhui Agri. Sci. 42, 21(2014)

5. D.W. Jiang. The Necessity and Key Points of Urban Soil and Water Conservation Legislation. China SWCC, 12,5(2014) 